\title{
A Case of Rotational Vertebral Artery Syndrome Diagnosed with Color Doppler-Assisted Carotid Duplex Sonography Imaging
}

\author{
Se-Hyung Kim \\ Department of Otorhinolaryngology-Head and Neck Surgery, Jeju National University School of Medicine, Jeju, Korea
}

\section{컬러 도플러 경동맥이중초음파검사를 이용하여 진단한 회전성 추골동맥증후군 1 예}

김 세 형

제주대학교 의학전문대학원 이비인후과학교실

\author{
Received June 14, 2016 \\ Revised August 11, 2016 \\ Accepted August 12, 2016 \\ Address for correspondence \\ Se-Hyung Kim, MD, PhD \\ Department of Otorhinolaryngology- \\ Head and Neck Surgery, \\ Jeju National University \\ School of Medicine, \\ 15 Aran 13-gil, Jeju 63241, Korea \\ Tel $+82-64-717-1720$ \\ Fax $+82-64-717-1131$ \\ E-mail meddoc98@gmail.com
}

Rotational vertebral artery syndrome (RVAS) is characterized by recurrent attacks of paroxysmal vertigo, nystagmus, and syncope elicited by head-rotation induced compression of the dominant vertebral artery (VA). Although the cause of RVAS could be explained by transient ischemic attacks within the vertebrobasilar territory, the exact underlying mechanism of the certain specific unilateral lesion of superior vestibular labyrinth responsible for the unidirectional nystagmus is still unclear. This study reports on a patient with right VA hypoplasia, in whom rightward head rotation led to stereotypic clinical symptoms of RVAS including recurrent attacks of vertigo and prominent right beating nystagmus. This patient could be diagnosed with color Doppler-assisted carotid duplex sonography imaging without using of dynamic neck angiography. Carotid duplex ultrasound is rapidly applicable, readily available, safe, real-time monitoring, noninvasive imaging procedure. Color Doppler-assisted carotid duplex sonography imaging therefore should be considered as the first-line diagnostic method in the detection of RVAS.

Korean J Otorhinolaryngol-Head Neck Surg 2016;59(11):796-801

Key Words Carotid duplex ultrasound · Rotational vertebral artery syndrome.

\section{서 론}

회전성 추골동맥증후군(rotational vertebral artery syndrome, RVAS)은 머리를 회전하거나 머리의 위치가 변할 때 일시적으로 어지럼증, 안진, 실신 등의 증상이 반복적으로 발 생하는 드문 질환이다. ${ }^{1)}$ 특징적인 머리의 자세로 인해 증상이 유발되어 "Bow Hunter syndrome"이라 불리기도 한다. 보통 일측 추골동맥의 무형성증(aplasia)이 있거나 형성저하증(hypoplasia)이 있는 환자에서 주로 발생하고, 이런 환자에서는 평소 반대쪽의 추골동맥이 뇌의 혈액 공급을 주로 담당하게 된다. 그러나 환자가 추골동맥이 좁은 쪽으로 머리를 회전하 게 될 때 주된 혈류를 공급하는 반대측의 우세한 추골동맥 에 신장과 압박이 생겨 혈류장애가 발생하고 이는 일시적인
척추뇌기저 혈류부전(vertebrobasilar insufficiency)을 초래 하여 전정계의 허혈증상이 유발된다.

RVAS는 아직까지 진단과 치료에 있어 확립된 지침은 없으 나 주로 역동성 혈관조영술(dynamic neck angiography)을 통해 진단하고 분명한 압박 부위가 확인된 경우 수술적 감압 술(surgical decompression) 등을 통해 증상이 호전되었음이 보고되었다. ${ }^{2)}$ 최근 저자는 운전 중 우측으로 고개를 돌릴 때 마다 발생하는 어지럼증을 주소로 내원한 환자에서 역동성 경부 혈관조영술 시행이 불가하여 컬러 도플러 경동맥이중초음 파검사(color Doppler-assisted carotid duplex sonography) 를 이용하여 RVAS를 진단한 증례를 경험하였기에 문헌고찰 과 함께 보고하고자 한다. 


\section{증 례}

67세 여자 환자가 9개월 전부터 발생한 우측으로 고개를 돌릴 때 발생하는 회전성 어지럼을 주소로 내원하였다. 평소 자가 운전을 하고 다니는 환자는 운전 중 신호대기 시 우측으 로 고개를 돌려 동반자와 애기를 나눌 때 갑자기 어지러운 증 상이 발생함을 호소하였다. 평소 잠을 잘 때에도 높은 베개를 사용하면 어지럼이 발생하였고 아침에 머리가 무거운 느낌이 든다고 하였다. 1 년 전부터 고지혈증 약을 복용하고 있는 것 이외에 다른 기저질환은 없었다.

이학적 검사상 양측 고막은 정상 소견을 보였고, 순음청력 검사에서는 노화에 의한 고주파영역의 감각신경성 난청을 보 였으나 이명은 호소하지 않았다. 신경이과적 검사에서는 자 발 안진은 없었고 앉은 자세에서 좌측으로 고개를 돌렸을 때 는 증상이 없으나 우측으로 고개를 돌렸을 때 약 10초간 지 속되는 우측 안진이 발생하였다가 점차 사라졌다. 양온교대 온 도안진검사(bithermal caloric test)에서 좌측 수평 반고리관 의 $7 \%$ 마비를 보였으며, 비디오 안진검사에서 환자가 베개를
사용하고 바로 누운 상태에서 우측 안진이 관찰되었고, 누운 상태에서 좌측으로 고개를 돌렸을 때는 안진이 관찰되지 않 으나 우측으로 고개를 돌렸을 때는 우측을 향하는 안진이 발 생하였다(Fig. 1). 초기 진단으로 우측 수평반고리관의 양성돌 발성체위현훈을 고려하였으나 이학적 검사 결과가 일치하지 않았다. 경부 혈관들의 상태를 확인하고 하향 안진을 유발시 킬 수 있는 다른 중추신경계 병변의 가능성을 배제하기 위하 여 뇌 자기공명영상 및 자기공명 혈관조영술을 시행하였다. 그 결과 전반적인 우측 추골동맥의 선천적 형성저하증이 확 인되었다(Fig. 2A). 이에 RVAS 의심하에 역동성 혈관조영술 을 시행하고자 하였으나 심한 조영제 부작용을 경험한 과거 력이 있어 검사를 보류하였다. 이에 저자는 양측 추골동맥의 상태를 자세히 확인하고 진단에 도움을 받고자 컬러 도플러 경동맥이중초음파검사를 시행하였다. 검사 결과 양측 추골동 맥의 잔여 내경(residual lumen)은 우측이 $2.74 \mathrm{~mm}$ (정상범위: $3.44 \pm 0.59 \mathrm{~cm}$ ), 좌측이 $5.16 \mathrm{~mm}$ (정상범위: $3.71 \pm 0.58 \mathrm{~cm})^{3)}$ 로 우측이 좌측에 비하여 약 $47 \%$ 가량 좁아져 있는 것이 확인 되었다(Fig. $2 \mathrm{~B}$ and C). 또한 컬러 도플러를 이용하여 양측

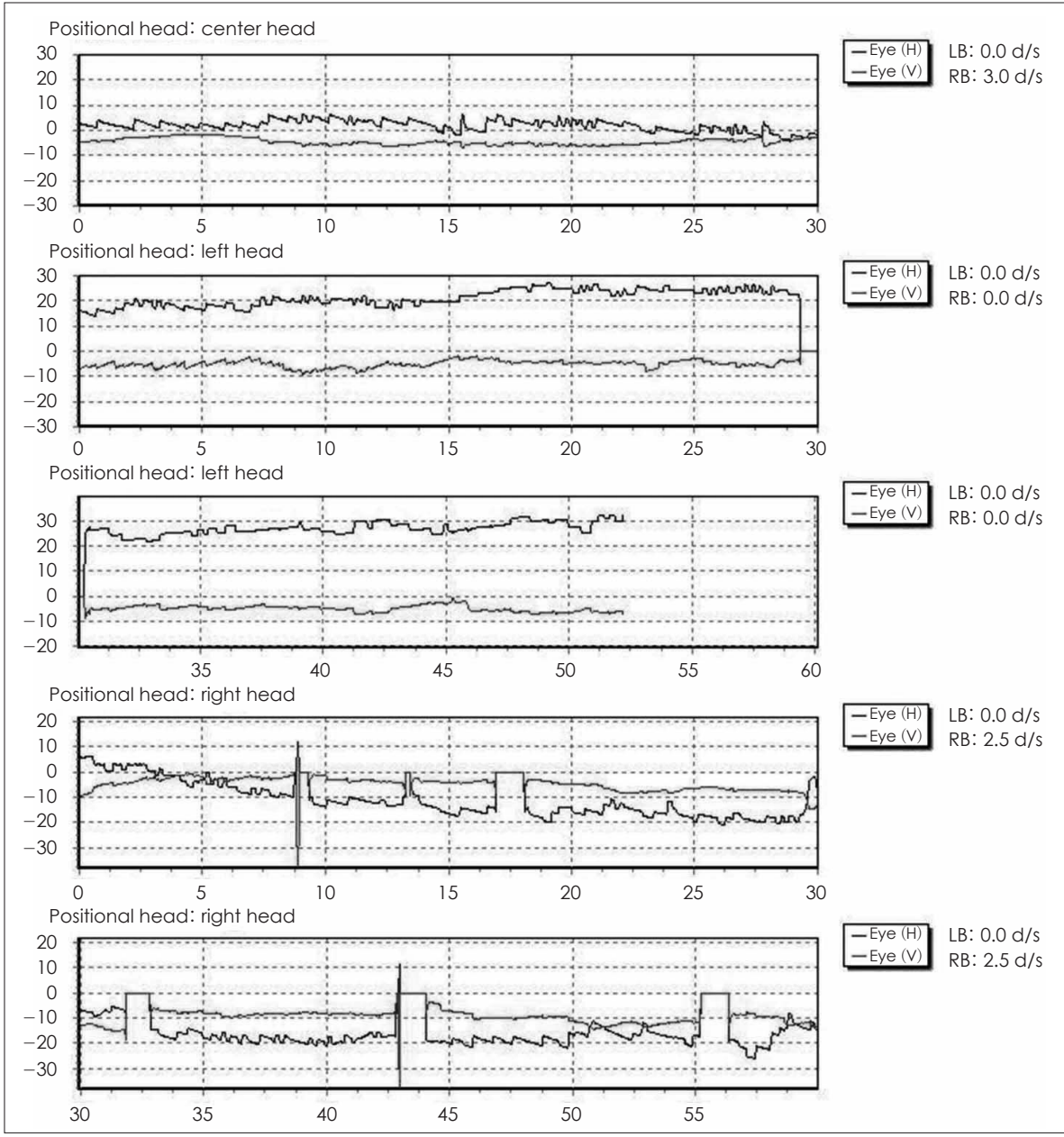

Fig. 1. Videonystagmographic finding. The supine head position with approximately 30 degrees of cervical flexion induces right beating nystagmus. The leftward head turning induces no nystagmus and then the rightward head turning induces right beating nystagmus. 

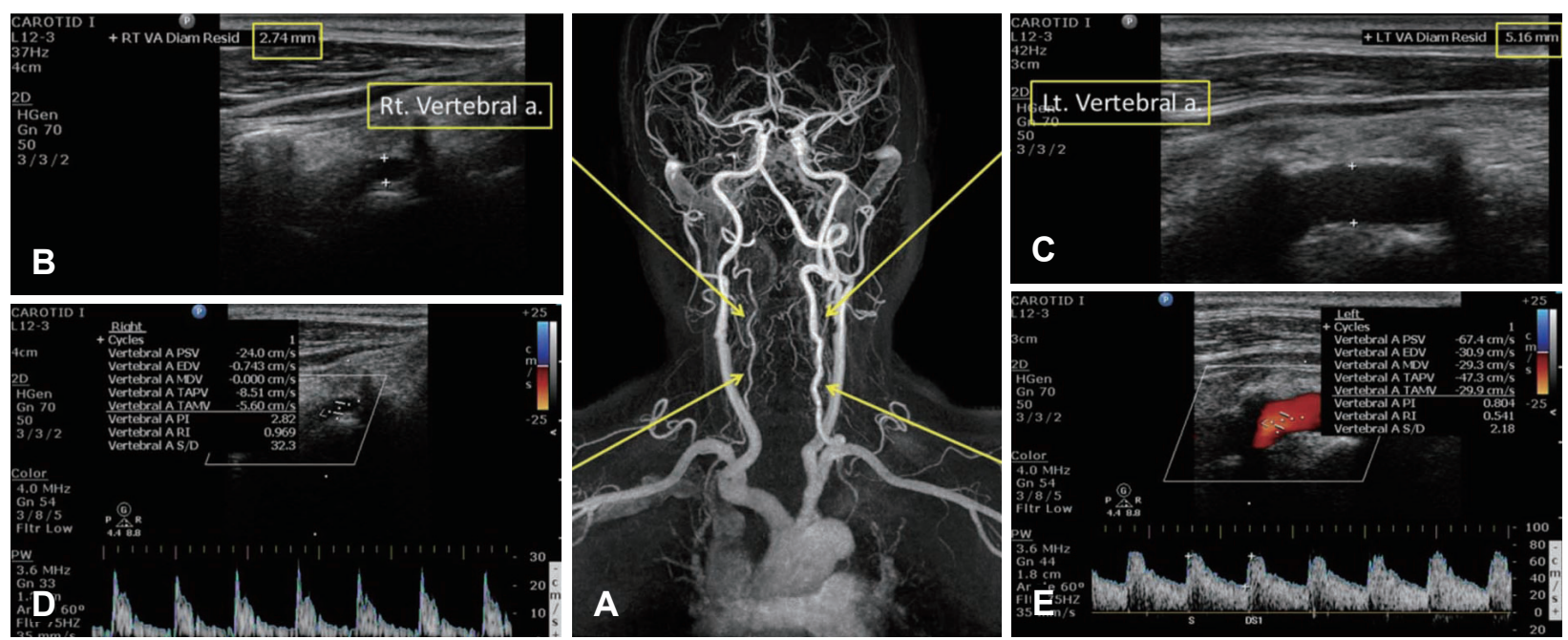

Fig. 2. Magnetic resonance angiographic finding of aortic arch revealed severe hypoplasia of right vertebral artery (A). Color Dopplerassisted carotid duplex sonography and magnetic resonance angiographic images displayed the measured diameters of residual lumen of vertebral arteries are $2.74 \mathrm{~mm}$ on the right side and $5.16 \mathrm{~mm}$ on the left side (B and $\mathrm{C})$. In the spectral Doppler findings, the measured peak systolic velocities of vertebral arteries at neutral position are $24.0 \mathrm{~cm} / \mathrm{s}$ in right side and $67.4 \mathrm{~cm} / \mathrm{s}$ in left side. During neck flexion, the minimum diastolic velocities of vertebral arteries are $0.0 \mathrm{~cm} / \mathrm{s}$ in right side and $29.3 \mathrm{~cm} / \mathrm{s}$ in left side (D and E). PSV: peak systolic velocity, EDV: end-diastolic velocity, MDV: minimum diastolic velocity, TAPV: time-averaged peak velocity, TAMV: time-averaged mean velocity, PI: pulsatility index, RI: resistance index, S/D: systolic-diastolic ratio.

추골동맥의 혈류속도, 파형, 방향을 확인하였고, 각각의 최대 수축기 속도(peak systolic velocity), 이완기말 속도(end-diastolic velocity), 최저 이완기 속도(minimum diastolic velocity) 등을 측정하였다. 그 결과 우측 추골동맥의 최대 수축

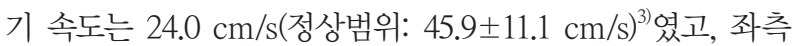
의 속도는 $67.4 \mathrm{~cm} / \mathrm{s}$ (정상범위: $51.5 \pm 13.3 \mathrm{~cm} / \mathrm{s})^{3)}$ 로 확인되었 다(Fig. 2D and E). 한편, 높은 베개를 사용하여 환자의 머리 를 약 30 도 정도 앞으로 숙이는 자세를 취한 상태에서 검사 를 하였을 때 우측 추골동맥의 최저 이완기 속도는 $0.0 \mathrm{~cm} / \mathrm{s}$ (정상범위: $13.8 \pm 4.6 \mathrm{~cm} / \mathrm{s})^{3}$ 였고 좌측 추골동맥의 속도는 $29.3 \mathrm{~cm} / \mathrm{s}$ (정상범위: $16.1 \pm 5.8 \mathrm{~cm} / \mathrm{s}$ ) 로 측정되었다. 이를 통 해 우측 추골동맥의 혈류속도가 머리의 위치 변화에 따라 일시적으로 현저히 감소하는 양상이 확인되었고, 이때 환자 도 검사 중 주관적인 어지럼증의 발생을 호소하였다. 그 외 양측의 내경동맥, 총경동맥, 외경동맥의 혈류속도, 파형, 방 향은 정상 소견을 보여 이에 RVAS로 진단하였다. 환자의 증 상이 우측 추골동맥의 특정부위에 명확한 압박이 존재하여 유발되는 상황이 아니었기에 수술적 치료는 고려하지 않았 고, 지질강하제와 항응고요법 치료를 시작하며 경과를 관찰 하기로 하였다. 그리고 환자에게 우측으로 고개를 돌릴 때 머리를 천천히 움직이게 하고 운전시 고개만 돌리지 말고 몸 을 전체적으로 회전하는 자세를 취하도록 교육하였다. 경구 항혈소판제(antiplatelet drug) 복용 3개월 후 환자는 우측으 로 고개를 돌릴 때 발생하는 안진이 비디오 안진검사에서 지 속적으로 관찰되나 이전보다 안진의 강도가 약해졌고 지속시
간도 짧아졌다(Fig. 3). 환자의 일상생활, 특히 운전 중 어지럼 증 또한 이전보다 호전되었고 다른 합병증 없이 외래 추적 관 찰 중이다.

\section{고 찰}

RVAS는 머리를 회전할 때 유발되는 반복적인 어지럼증, 안 진, 실신, 오심, 복시, 감각운동장애(sensorimotor disturbance) 등이 특징적인 질환이다. ${ }^{1,2}$ 한쪽 추골동맥의 형성저하증 혹 은 무형성증, 또는 내강의 폐쇄가 있는 상태에서 환측으로 머 리를 과하게 회전할 경우 척추뇌기저 동맥의 혈류 공급이 차 단되어, 척추뇌기저순환(vertebrobasilar circulation)의 담당 영역에 일과성허혈발작(transient ischemic attack)이 발생하 게 되고 그에 따른 증상들이 유발되는 것으로 알려져 있다. ${ }^{4}$ 이 질환은 후방순환 허혈성 뇌경색(posterior circulation ischemic stroke) 및 이에 동반되는 영구적인 신경학적 결손의 발 생과 높은 상관관계가 있는 것으로 보고된다. ${ }^{5}$

한편 이전 보고에 의하면, 정상인의 경우에도 약 $9 \%$ 에서 머 리 회전시 동측 혹은 반대측에 추골동맥의 폐쇄가 일시적으 로 발생하지만 증상은 전혀 없는 것으로 보고되었다.) 따라 서 RVAS가 발생하기 위해서는 다양한 선천적 혹은 후천적 원인에 의해 일측 추골동맥의 혈류가 감소되어 반대측 추골 동맥이 후방순환의 주된 역할을 담당하고 있는 상태에서, 머 리를 회전하는 순간 우세한 추골동맥이 압박되고, 그 결과 후 방순환 혈류가 감소되어 일련의 일과성 허혈성 증상들이 발 


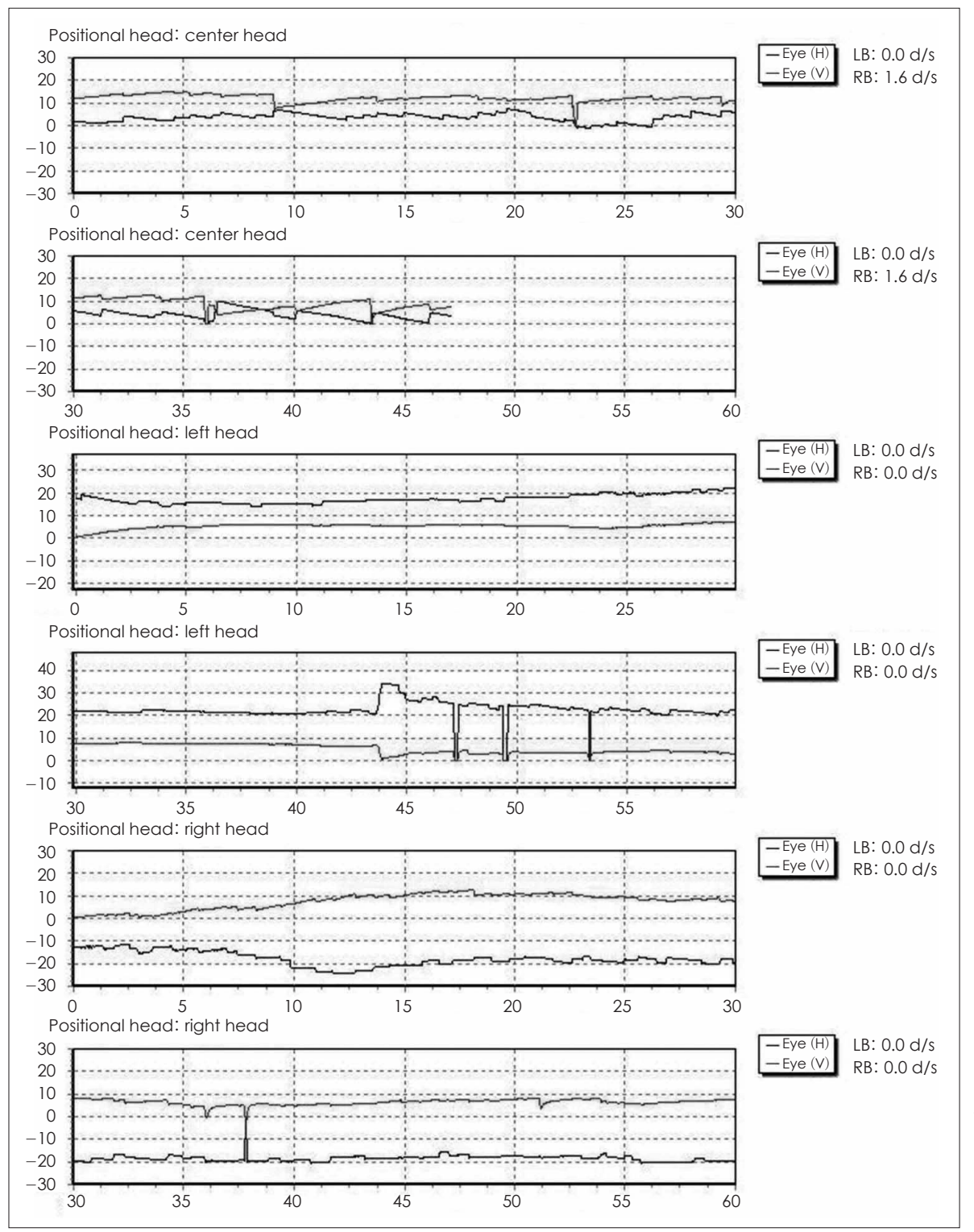

Fig. 3. Videonystagmographic finding after anticoagulation medication. The supine head position with approximately 30 degrees of cervical flexion induces right beating nystagmus. The leftward head turning induces no nystagmus and then the rightward head turning induces right beating nystagmus.
생하는 것으로 추측할 수 있다. 이러한 혈류감소를 일으킬 수 있는 상태로는 고리중쇠관절(atlantoaxial joint)에서 머리 회 전에 의해 제 1 경추(atlas)가 회전하고 이때 추골동맥의 주행 경로가 신장(stretch)되고 외부 압박(extrinsic compression) 을 받게 되어 발생하는 경우가 가장 흔한 것으로 알려져 있 다. 최근 Schelfaut 등 ${ }^{7}$ 의 연구에서는 제3경추보다 아래에서 가로구멍(transverse foramen)의 입구 혹은 가로구멍 내에 압박 부위가 존재한다면 환측으로 회전할 때 증상이 발생하 고, 압박 부위가 제2경추 또는 그보다 윗 부분에 존재한다면 정상측으로 회전할 때 발생할 수 있다고 보고하였다. 이러한 골성 융기(bony prominence) 외에도 추골동맥 주변의 근육 혹은 인대와 같은 섬유성 띠(fibrous band)에 의한 압박, 경추 의 척추관절강직증(cervical spondylosis) 등이 증상을 유발
할 수 있는 것으로 알려져 있다. 따라서 RVAS의 환측을 결정 함에 있어 증상을 유발하는 머리의 회전방향만을 고려한다 면 이는 임상적으로 한계가 있음을 주지하여야 한다.

한편, 우세한 추골동맥의 압박은 뇌기저동맥(basilar artery) 의 혈류를 감소시키고 이는 결과적으로 양측의 전하소뇌동 맥(anterior inferior cerebellar artery)과 내이동맥(internal auditory artery)의 허혈을 초래하므로 양측에서 중추성 혹은 말초성 청각전정기관 전체의 기능 저하가 유발됨이 이론적으 로 타당하다. 그러나 이전 연구들에 따르면 어지럼증만이 유 일한 증상으로 나타나는 RVAS에서는 대부분 하향안진이 관 찰되는 것으로 보고하였다. ${ }^{89}$ 이는 일시적인 전정계의 허혈이 양측 혹은 일측의 상전정미로(superior vestibular labyrinth) 를 흥분시켜 하향안진이 발생하는 것으로 추측되고 있다. 
해부학적으로 상전정미로는 내이동맥의 분지인 전전정동맥 (anterior vestibular artery)에 의해 혈액 공급을 받는 상반고 리관, 수평반고리관 및 난형낭 부위를 의미하며, 전전정동맥 은 특징적으로 내이의 다른 혈관들에 비하여 골성 측부혈행 순환(intraosseous collateralization)이 덜 발달되어 상전정미 로가 허혈 손상에 좀 더 취약하기 때문이다. 그러나 드물게 우세한 추골동맥의 압박으로 환측을 향하는 수평성 혹은 회 선성 안진과 같은 일측성 말초성 안진만이 유발되는 경우에 있어서는, 양측성이지만 다소 비대칭적인(slightly asymmetric) 상전정미로 자극에 의해 발생하는 것으로 설명하고자 하는 보고가 있다. ${ }^{4}$ 본 증례에서도 하향안진은 관찰되지 않 았고, 머리를 우측으로 돌릴 때 우향안진이 발생하였다. 이는 우세한 좌측 추골동맥이 압박되면서 일시적으로 양측 미로 에 허혈이 발생하고 대칭적인 흥분성 신경자극이 유발되었으 나, 양측 수평반고리관에는 비대칭적 흥분이 유발된 것으로 추측된다. 본 증례의 경우 우측 미로에 더 많은 영향을 줌으 로써 수평성 우향안진이 발생한 것으로 생각된다.

허혈에 의한 RVAS의 증상이 실제적으로 말초성 전정기관 에서 기인하는지 혹은 중추성 전정기관에서 기인하는지 아 직 분명하게 밝혀져 있지 않다. 또한 환자 개개인의 내이 혈 관의 분포의 차이와 협착의 정도가 다양하기에 임상적으로 안진의 방향 역시 다양하게 나타날 수 있음을 고려해야 하고, RVAS의 진단에 하향안진이 필수적인 임상소견은 아님을 주 지할 필요가 있다.

본 증례의 진단에 사용된 컬러 도플러 경동맥이중초음파 검사는 경동맥 초음파(carotid duplex sonography)의 발전된 형태로, 혈관의 구조를 보는 고해상도 B-mode(brightness mode)와 동시에 혈류속도와 파형을 그래프로 측정한 후 수 치화하여 평가할 수 있는 분음 도플러 초음파(spectral Doppler ultrasonography)를 합친 검사 장비이다. 여기에 컬러 혈 류 영상(color flow image)이 더해지게 되어 혈류의 방향에 따라 초음파 입사방향에 대해 다가오는 혈류는 붉은색으로, 멀어지는 혈류는 푸른색으로 표시되고, 혈류의 속도에 따라 그 밝기를 나타내어 검사자가 보다 직관적으로 측정 결과를 파악할 수 있다. 본 증례에서 우측 추골동맥의 최대 수축기 속도는 $24.0 \mathrm{~cm} / \mathrm{s}$ 로 좌측에 비하여 $75 \%$ 가량 감소되어 있었 다. 또한 베개를 사용하여 고개를 숙인 자세에서 검사를 하 였을 때, 우측 추골동맥의 최저 이완기 속도가 $0.0 \mathrm{~cm} / \mathrm{s}$ 로 심 장의 이완기에 후방순환을 위한 추골동맥 혈류의 흐름이 거 의 존재하지 않음이 확인되었다. 이는 좌측의 최저 이완기 속 도인 $29.3 \mathrm{~cm} / \mathrm{s}$ 와 비교 시 분명한 차이가 있고, 이러한 결과 를 통해 환자의 머리 자세에 따른 척추동맥의 혈류 변화를 실시간으로 확인할 수 있다는 점에서 분명한 가치가 있는 진
단검사법이다. 기존의 국내외 문헌에 따르면 주로 역동성 혈 관조영술이 확진을 위한 표준 진단법으로 사용되고 있으나, 검사 자체가 침습적이고 환자에게 불편감을 유발하며, 방사 선에 노출되고 조영제를 사용해야 한다는 중대한 단점이 있 다. 이에 반하여 컬러 도플러 경동맥이중초음파검사는 비침 습적이고 쉽게 사용할 수 있으며, 방사선 노출이 없어 안전하 고, 무엇보다도 어지럼증의 발생을 유발하는 특정 머리 자세 에서 추골동맥의 혈류 감소도 실시간으로 확인할 수 있어 RVAS를 쉽고 빠르게 진단할 수 있다. 이 점에서 최적 표준 검사법으로서의 가능성이 충분하다 판단되며 본 증례를 통 해 주지하고자 한다.

RVAS의 치료는 우선적으로 항응고요법 약물치료와 목 돌 림의 제한 교육, 목 보호대(neck collar)의 사용과 같은 보존 적 치료가 권장되나, 이 경우 약 $50 \%$ 정도에서 뇌경색 혹은 기타 다른 신경학적 결함이 발생할 수 있다는 보고가 있어, ${ }^{6}$ 만약 환자의 나이가 젊고, 증상이 자주 발생하며, 추골동맥 의 압박이 심하게 관찰되는 경우에는 수술적 감압술이나 척 추유합술(vertebral fusion)이 적극적으로 권장된다. ${ }^{2)}$ 본 증 례에서는 양온교대 온도안진검사에서 양측 수평 반고리관의 마비는 없었지만 비디오 안진검사를 위하여 머리를 앞으로 30 도 정도 숙였을 때 3.0 degree/sec의 우측 안진을 관찰할 수 있었다. 이는 우측의 척추동맥의 혈류저하가 머리를 양측 으로 회전하였을 때만 발생하는 것이 아니라 특정 머리 위치 에 의해 유발될 수 있음을 증명하였고, 환자가 평소 수면 중 일부러 베개를 사용하지 않는 이유 역시 설명되었다. 이러한 안진은 이학적 검사 시 고개를 회전시키면 증상이 유발될 수 있어 양성돌발성체위현훈으로 오진될 수 있기에 주의가 필요 하고 특징적으로 환자가 앉아 있거나 서있는 상태에서 어지럼 증이 유발된다면 RVAS를 강력히 의심할 필요가 있다. ${ }^{8)}$ 또한 중추성의 어지럼증의 감별을 위하여 뇌 자기공명영상과 함 께 자기공명 혈관조영술 등의 영상학적인 진단은 반드시 시 행되어야 할 것으로 생각된다.

그리고 본 증례에서 환자는 고개를 우측으로 돌릴 때 뿐만 아니라 앞으로 숙일 때도 유사한 증상이 발생함이 이학적 검 사와 초음파검사를 통해 확인되었다. 이에 저자는 RVAS라는 명칭에서 단순히 “회전성(rotational)”이 아니라, 다양한 머리 위치 변화에 의해 유발되는 "두위변환성 추골동맥증후군(head position induced vertebral artery syndrome)"이 더 정확한 진단명일 수 있음을 제안한다.

\section{REFERENCES}

1) Schuette AJ, Barrow DL. Rotational vertebral artery syndrome. World Neurosurg 2013;79(5-6):680-1.

2) Kang HS, Ahn SK, Hur DG, Hwang SH. A case of rotational vertebral 
artery syndrome treated by posterior cervical decompression. Korean J Otorhinolaryngol-Head Neck Surg 2012;55(2):107-10.

3) Seidel E, Eicke BM, Tettenborn B, Krummenauer F. Reference values for vertebral artery flow volume by duplex sonography in young and elderly adults. Stroke 1999;30(12):2692-6.

4) Marti S, Hegemann S, von Büdingen HC, Baumgartner RW, Straumann D. Rotational vertebral artery syndrome: 3D kinematics of nystagmus suggest bilateral labyrinthine dysfunction. J Neurol 2008;255(5): 663-7.

5) Lu DC, Zador Z, Mummaneni PV, Lawton MT. Rotational vertebral artery occlusion-series of 9 cases. Neurosurgery 2010;67(4):106672; discussion 1072.
6) Choi KD, Shin HY, Kim JS, Kim SH, Kwon OK, Koo JW, et al. Rotational vertebral artery syndrome: oculographic analysis of nystagmus. Neurology 2005;65(8):1287-90.

7) Schelfaut S, Verhasselt S, Carpentier K, Moke L. Subaxial rotational vertebral artery syndrome: resection of the uncinate process and anterior fusion can be sufficient!: case report and review of the literature. J Spinal Disord Tech 2015;28(2):66-70.

8) Kim HA, Yi HA, Lee CY, Lee H. Origin of isolated vertigo in rotational vertebral artery syndrome. Neurol Sci 2011;32(6):1203-7.

9) Strupp M, Planck JH, Arbusow V, Steiger HJ, Brückmann H, Brandt T. Rotational vertebral artery occlusion syndrome with vertigo due to "labyrinthine excitation". Neurology 2000;54(6):1376-9. 